\title{
Lazos de sol y sombra. Octavio Paz y Chile
}

\author{
Fabienne Bradu \\ Instituto de Investigaciones Filológicas, UNAM \\ fabbra@gmail.com
}

\begin{abstract}
RESUMEN: Este ensayo propone un recuento de las relaciones entre Octavio Paz y algunos poetas y artistas de Chile, desde su participación en el Congreso Antifascista de Valencia, en 1937, hasta su muerte en 1998. Aunque nunca le fue posible viajar a Chile, Octavio Paz dedicó numerosas y espléndidas páginas a Gabriela Mistral, Vicente Huidobro, Pablo Neruda, Roberto Matta y Gonzalo Rojas. En ellas expresa su juicio crítico de las obras de estos chilenos así como sus relaciones personales con algunos de ellos. Este recuento también abarca las batallas que Octavio Paz emprendió en su búsqueda poética y en la historia del siglo $\mathrm{xx}$.
\end{abstract}

АвSTRACT: This essay proposes an account of relationshps between Octavio Paz and number of poets and artists in Chile, from the time of his participation in the Antifascist Congress of Valencia, in 1937, until his death in 1998. Although he would never be able to travel to Chile, Octavio Paz dedicated numerous splendid pages to Gabriela Mistral, Vicente Huidobro, Pablo Neruda, Roberto Matta and Gonzalo Rojas. They express his critical judgment for the works of these Chileans as well as his personal relationships with some of them. This account also covers the various battles Octavio Paz undertook in his poetical search and in the history of the $20^{\text {th }}$ century.

Palabras clave: Octavio Paz, siglo xx, poesía chilena, Gabriela Mistral, Vicente Huidobro, Pablo Neruda, Roberto Matta, Gonzalo Rojas.

KeYwords: Octavio Paz, $20^{\text {th }}$ century, Chilean poetry, Gabriela Mistral, Vicente Huidobro, Pablo Neruda, Roberto Matta, Gonzalo Rojas.

Entre la vida inmortal de la vida y la muerte inmortal de la historia hoy es cualquier día...

Octavio Paz, "Lauda”

Aunque resulte difícil creerlo, la primera incursión de Octavio Paz hacia el sur de América data de 1955, pero la aventura no lo llevó más allá de la isla de Santo Domingo, es decir, prácticamente a la misma 
latitud del Yucatán mexicano. Solo hasta abril de 1985 visitó por primera vez Argentina, invitado por el periódico La Nación, y participó en una Semana Cultural junto con Jorge Luis Borges, Mario Vargas Llosa y José Bianco. El viaje prosiguió hasta Brasil y Uruguay, pero Chile estuvo excluido del periplo a causa de la permanencia del general Pinochet en el poder, una presencia más disuasiva para el Nobel que el dios mexica Huitzilopochtli. A pesar de que nunca pisó tierra chilena, cultivó con los poetas de Chile una apasionada y prolongada relación que literalmente se detuvo el día de su muerte, el 19 de abril de 1998. "Yo he tenido suerte con los poetas chilenos", escribió Octavio Paz en un texto motivado por el centenario de Gabriela Mistral ("El pan, la sal y la piedra: Gabriela Mistral”, en 1993c: 172). En efecto, conoció sucesivas temporadas de encantamiento con Vicente Huidobro, Pablo Neruda, Gabriela Mistral, Gonzalo Rojas y el pintor Roberto Matta; los conoció a todos y, recíprocamente, ellos le manifestaron estima y afecto en distintos grados. A cada uno de estos nombres corresponde una época y una batalla de Octavio Paz para fijar su poética y situarse en la Historia del continente. Hay que decirlo de entrada: la "suerte" a la cual alude, también entraña un ominoso revés que culminó con un episodio pirotécnico cuando dos de los volcanes de la poesía en lengua española hicieron erupción en cada extremo de la América Latina.

No obstante su desconocimiento físico del país, bajo su pluma, el paisaje de Chile se hace presente cuando trata de imaginar de dónde surge la poesía de Gabriela Mistral, a quien concibe bajo la especie de una gran madre continental, como si Chile atesorara las mismas diosas cautivadoras y terribles del México prehispánico: "La poesía de Gabriela Mistral es un manantial que brota entre rocas adustas en un alto paisaje frío pero calentado por un sol poderoso" (172). Al igual que otros jóvenes poetas de Hispanoamérica, Octavio Paz había mandado a la Nobel su libro Libertad bajo palabra (1949) y, al igual que casi todos, había recibido, a vuelta de correo, unas líneas entusiastas y generosas. La había conocido en París, en 1946, y durante una conversación, ella lo previno sobre los peligros del cosmopolitismo. Una advertencia inesperada de parte de quien llevó una vida de nómada fuera de su país natal. Pero su mayor virtud poética, recalca Octavio Paz, consiste precisamente en no haber olvidado nunca su sabor nativo. A esta fidelidad se suma su apartamiento de las aventuras estéticas de su tiempo, así como de las disputas ideológicas que tergiversaron los 
genuinos debates poéticos. A su juicio, la chilena podría equipararse con Alfonso Reyes y Ramón López Velarde por la continuidad y la renovación que aportaron al Modernismo, sin participar ya del movimiento encabezado por Rubén Darío. Otra de las virtudes de la poesía mistraliana es la presencia de la prosa en el verso. Puntualiza Paz: "En ciertos momentos privilegiados, sin cesar de ser música verbal, el verso adquiere una densidad que lo lleva no a disiparse en el aire sino a caer, con una suerte de hermosa fatalidad, para enterrarse y fructificar. Es la ley de la gravedad espiritual de la poesía" (175). En el texto "El pan, la sal y la piedra: Gabriela Mistral” que escribió en 1988, en ocasión del centenario de su nacimiento, Octavio Paz lamenta el olvido que castiga la obra de la chilena: "Hoy se lee poco a Gabriela Mistral: su obra no padece en el purgatorio de la literatura sino en su limbo. Este olvido es un signo, uno más, de la frágil memoria histórica de los hispanoamericanos [...] Olvidarla es olvidar una de nuestras fuentes. Más que una falta de cultura es un pecado espiritual". La denomina "la poetisa de los misterios cotidianos", cuya voz le evoca otro paisaje que nunca vio: la piedra alzada sobre el trasfondo de la cordillera, que constituye la lápida de Gabriela Mistral en Montegrande. Para cualquiera que haya visitado esta tumba digna y adusta, resultan elocuentes las líneas del mexicano: "Sobria y apasionada, su voz tiene una tonalidad religiosa, incluso cuando habla de asuntos profanos. [...] En Gabriela Mistral hay ecos inconfundibles de la Biblia, una voz que echo de menos en casi toda nuestra poesía moderna. Dije: voz viril; agrego ahora: voz de varona, voz de Judith o de Esther. Profunda y poderosa voz de montaña mujeril" (173). Pese a esta reivindicación, la de Gabriela Mistral es una voz poco presente en la poesía y las inquietudes de Paz. Fuera de este texto que se antoja más justiciero que íntimo, no hay huella perceptible de una eventual influencia de Gabriela Mistral en la tonalidad paciana. En cambio, el fantasma nerudiano recorre más de un verso del joven Paz quien, a la par de casi todos los poetas de su generación en Hispanoamérica, difícilmente se sustrajo al sortilegio avasallador del autor de Residencia en la tierra.

Hay que remontar a la Guerra Civil española que movilizó a los poetas hispanoamericanos de una manera mucho más urgente que la Segunda Guerra Mundial, para hallar el origen de los lazos de Octavio Paz con Chile. En 1937 Octavio Paz recibió una invitación para participar en el 
Congreso Internacional de Escritores Antifascistas que había de realizarse en el verano de Valencia. Varios habrían podido reclamar para sí la iniciativa de la invitación: Rafael Alberti, que había conocido al joven Paz durante su viaje a México en 1934; el poeta español Arturo Serrano Plaja, estricto contemporáneo y lector del mexicano; y Pablo Neruda, quien siempre reivindicó como una hazaña propia el "descubrimiento" del poeta de 23 años. A todos ellos Octavio Paz había mandado, meses antes del viaje, su libro de poemas Raiz del hombre. Entre las muchas figuras que acudieron al Congreso de Valencia, Vicente Huidobro lo impresionó sobremanera: "Huidobro me dio un abrazo y me saludó a la francesa. Era totalmente afrancesado y me dio dos besos. No pude hablar apenas con él" (citado por Sheridan: 259). Cabe recordar este encuentro que Pablo Neruda se empeńó en opacar en su momento, como si hubiese querido borrar, en vano, la presencia de su rival en España y en la obra posterior de su "protegido".

A su regreso a México, Octavio Paz publica en la revista Ruta su primer ensayo sobre Pablo Neruda, simbólicamente titulado: "Pablo Neruda en el corazón" (1938). Allí se explaya sobre sus afinidades con el autor de Residencia en la tierra y España en el corazón, que a sus ojos aliaban la poesía que nunca cesará de admirar en el chileno, y la causa histórica por la cual Paz pretendió jugarse la vida (subrayemos, como un dato extraño, que la República española cayó el 31 de marzo de 1939, el día en que Paz cumplía sus 25 años). Curiosamente, se reiteran en este primer texto dos palabras poco frecuentes en la prosa de Paz: "ternura" y "tiernamente", que cifran la temperatura afectiva de su afinidad. Por su lado, entre 1938 y 1941, Pablo Neruda colaboró dos veces en la revista Taller que dirigía el joven poeta en México, a quien aventajaba una década de edad y una considerable experiencia poética. Durante la estancia de Pablo Neruda en México como Cónsul General de Chile (agosto 1940-agosto 1943), las relaciones se estrecharon en los primeros meses: "Neruda era generoso y su inmensa cordialidad no tenía más defecto que el de su mismo exceso; su afecto, a veces, aplastaba como una montaña”, recuerda Paz (1993c: 84), pero pronto, casi en seguida, la amistad se deterioró a raíz de la salida, en la editorial Séneca, a mediados de 1941, de la antología de poesía Laurel, preparada por Xavier Villaurrutia, Octavio Paz, Emilio Prados y Juan Gil-Albert, a petición de José Bergamín. Pablo Neruda y León Felipe se negaron a aparecer en la antología por sus diferencias con José Bergamín y otras 
susceptibilidades ajenas a la poesía pero, como suele suceder, enseguida transformaron la negación en un agravio. No hicieron falta pretextos para justificar las hostilidades que se desataron entre un bando y otro: la inclusión de Huidobro en la antología despertó la cólera de Neruda, pero luego, en unos versos del Canto General, aducirá la ausencia de Miguel Hernández o la presencia de Juan Ramón Jiménez como las centellas que prendieron la mecha de su ira.

Octavio Paz explicó larga y detalladamente cómo el episodio de Laurel terminó en un conato de pugilato al final de una cena: "La cena fue en el Centro Asturiano. Había varias mesas y mucha gente: escritores, artistas, periodistas y, detalle curioso, varios agrónomos (Pablo se había interesado en la Reforma Agraria). Busqué sitio en un extremo y me senté al lado de Julio Torri y José Luis Martínez. Hubo discursos tronitonantes y brindis exaltados. A la salida nos formamos en fila para despedirnos de Pablo, que conversaba con Clemente Orozco, González Martínez y otras notabilidades. Había bebido. Cuando llegó mi turno, me abrazó, me presentó con Orozco, elogió mi camisa blanca — "más limpia", agregó, "que tu conciencia" - y enseguida comenzó una interminable retahíla de injurias en contra de Laurel, Bergamín y, claro, contra los otros autores de la maldita antología. Lo interrumpí, estuvimos a punto de llegar a las manos, nos separaron y unos refugiados españoles se me echaron encima para golpearme. Mi amigo José Iturriaga los puso en fuga con dos guantadas. Entonces intervino Enrique González Martínez, que me cogió del brazo y salió conmigo y con Alí Chumacero, José Luis Martínez y José Iturriaga. En la calle me sentí abatido y roto, 'como un camarero humillado, como una campana un poco ronca, como un espejo viejo"' (86-87). Siguieron espadazos por escrito, una "Despedida a un cónsul" en Letras de México por parte del mexicano y unos versos denostadores en el Canto General y, sobre todo, un incómodo silencio de veinticinco años. La reconciliación tuvo lugar hasta 1967, a raíz del Festival Internacional de Poesía de Londres, en un pequeño hotel de Cadogan Gardens. Éstos son los elementos anecdóticos de una de las más famosas peleas poéticas del siglo xx.

Más allá de la tiranía de las vanidades, existían sólidos argumentos que justificaban el alejamiento de Paz con respecto a la poesía y la persona de Neruda. Con leve antelación a sus contemporáneos chilenos, Octavio Paz resaltaba dos principales defectos en la producción poética de Neruda: la ideología y la abundancia. Acerca del primero fijó su 
postura que conllevaba la denuncia: "La poesía de la historia no puede confundirse con la propaganda a favor de ésta o aquella causa, aún si esa causa fuese la mejor del mundo. Esto es lo que, todavía, se obstinan en ignorar los atardados seguidores de Neruda. La poesía de la historia tampoco puede consistir en el comentario moral o cínico del poeta didáctico o del satírico. La poesía de la historia brota, no de saber que estamos ante la historia sino en ella: somos historia" ("Poesía e historia: Laurel y nosotros", 1993c: 117). Y luego venía el reproche expreso contra Neruda: "La poderosa máquina de propaganda de los partidos comunistas y la influencia que tuvo durante la postguerra la ideología llamada de izquierda, lo convirtieron en una figura pública. Fue un ídolo o, más exactamente, un mito. Pero los mitos tienden fatalmente al estereotipo y Neruda no escapó a la estatua de cartón. En sí misma, la actividad política no tenía por qué haberlo dañado: pensemos en Milton o en Víctor Hugo. Pero Neruda no supo guardar las distancias con los jerarcas de su partido" (112). En cuanto al segundo defecto, llamado abundancia, Paz argumenta: "lo dañó porque le hizo confundir la facilidad con la inspiración" y ejemplifica: "Publicó muchos libros, algunos malos de veras y otros desiguales como el escarpado y difuso Canto General, gran olla en donde hay de todo: hundimos la mano y sacamos pájaros de cuarzo, silbatos de plumas, conchas irisadas, pistolas oxidadas, cuchillos rotos, ídolos descalabrados. Arengas, diatribas, kilómetros de lugares comunes y de pronto, sin aviso, luminosos y arrebatadores, manojos de esplendores recién cortados, intactos y todavía vivos" (112). Califica de "admirables" algunas de las Odas elementales y de "singular" el Estravagario porque "logra algo muy difícil: la sonrisa del taciturno". Pero después de detallar lo malo y lo bueno, añade una reivindicación de la obra de Pablo Neruda, que solía reiterar en sus conversaciones finales, asegurando que, bien editado, el chileno sin duda surgiría como el más grande poeta hispanoamericano del siglo xx, lo cual significaba: por encima de su propia obra. Así lo consignó por escrito para la posteridad incrédula:

Me ha parecido necesario apuntar todos estos reparos para decir lo que desde hace mucho quiero decir: Pablo Neruda es el poeta más amplio, hondo y humano de su generación, en América y en España. No digo que sea el más perfecto sino el más vasto y variado; también, con frecuencia, el más intenso, ora desgarrador, ora risueńo, a un tiempo sim- 
ple y misterioso. Un poeta inmenso. En cada uno de sus libros, aún en los más flojos, hay poemas inolvidables; en cada uno de sus poemas, aún los menos afortunados, hay líneas que son relámpagos de verdad. Quiero decir: relámpagos verdaderos que iluminan brevemente nuestra conciencia y trazan tatuajes en nuestra memoria; asimismo, relámpagos con la luz de una verdad súbita. ¿Qué verdad? Una verdad oculta, olvidada o abandonada, enterrada o acabada de nacer. La verdad de todos los días, la verdad de cada día, que pasa como nosotros pasamos y se queda como los dibujos del tiempo sobre la roca (113).

¿Cuál habría sido su propia edición de la obra de Neruda? Sin duda habría eliminado la contaminación ideológica, pero también habría dejado la escoria que acarrea el poderoso oleaje verbal, el cual "arrastra todos esos elementos [impuros], los levanta, los deja caer, los muele y los extiende sobre la página: playa cubierta de cetáceos gigantes" (112). En su defensa de la poesía "impura" contra la exquisitez excluyente de un Juan Ramón Jiménez, Neruda había ganado la batalla que aprovecharía la generación que le seguía, es decir, aquella que integraba Paz y, en Chile, su "hermano de horizonte" Gonzalo Rojas.

Al igual que el autor de La miseria del hombre, Octavio Paz había participado en las vanguardias de la juventud de su siglo y, pese a la subsecuente distancia crítica, nunca renegó de su interés por los experimentos de los límites. Por ello, y no solamente para restar importancia a Pablo Neruda como se pensaría, dedicó varios ensayos a la poesía de Vicente Huidobro. En El arco y la lira, deslinda la revolución que causaron los dos chilenos rivales en la poesía de las primeras décadas del siglo xx: "La vanguardia tiene dos tiempos: el inicial de Huidobro, hacia 1920, volatilización de la palabra y la imagen: y el segundo de Neruda, diez años después, ensimismada penetración hacia la entraña de las cosas. [...] La historia del 'modernismo' se repite. Los dos poetas chilenos influyeron en todo el ámbito de la lengua y fueron reconocidos en España como Darío en su hora" (1993a: 113). Como era su costumbre para situar a un poeta, Octavio Paz toma el asidero de Darío para enfatizar lo que cada chileno aporta a la historia de la poesía en lengua española: "Podría agregarse que la pareja Huidobro-Neruda es como un desdoblamiento de un mítico Darío vanguardista, que correspondería a las dos épocas del Darío real: Prosas profanas, Huidobro; Cantos de vida y esperanza, Neruda" (113). Tampoco puede dejar de evocar a Pierre 
Reverdy, el aliado y contrincante de Vicente Huidobro, en una carta a Jaime García Terrés: "Para un hispanoamericano, es difícil hablar de Reverdy sin recordar a Vicente Huidobro. Fueron muy amigos por una corta temporada, editaron juntos una revista famosa y acabaron por pelearse. El genio poético es irascible", escribe Octavio Paz recordando tal vez su propia pelea con Pablo Neruda. Y prosigue:

Las deudas de Huidobro con la poesía francesa, especialmente con Apollinaire y Reverdy, son indudables, pero su obra es única e inconfundible, lo mismo en castellano que en francés. Aunque el punto de partida de Huidobro fue el mismo que el de Reverdy, su evolución poética fue diametralmente opuesta a la del poeta francés. Son distintos hasta en sus defectos: Huidobro nos cansa a fuerza de brillo y exageraciones. Reverdy nos llega a parecer opaco, monótono en sus repeticiones. Temperamentos no sólo diferentes sino antagónicos: el chileno fue un poeta exterior, viajero lanzado a todos los espacios; [...] el francés fue un poeta del objeto interior y en su mundo, más intenso que extenso, las eternidades se llaman instantes y el infinito es una mancha de tinta vista a la luz de una lámpara (1993b: 456).

Más inesperadamente aún, equipara a Vicente Huidobro con el peruano César Vallejo, a quien había conocido en el Congreso de Valencia, porque ambos encarnaban la negación radical del Modernismo, aunque estuviesen "empeñados en una exploración psíquica y verbal opuesta: el minero Vallejo y el aviador Huidobro [...] Es portentoso que los protagonistas de la aventura poética más extremada hayan sido un millonario aristócrata de Chile y un pequeño burgués del interior del Perú" ("Poesía e historia: Laurel y nosotros", 1993c: 98). Éste es el sello más singular del Paz ensayista: tender puentes entre poetas, entre tradiciones, entre culturas, que ensanchan las visiones aldeanas y miopes de la mayoría de los críticos literarios. No obstante la sorprendente conjunción, Octavio Paz inmediatamente singularizaba la aparición de Vicente Huidobro en las primeras décadas del siglo xx: "La irrupción de Vicente Huidobro en la poesía de nuestra lengua fue como una invasión de tártaros o mongoles: arrasó las viejas ciudades pero entre las piedras caídas surgió una nueva y más ligera vegetación poética. Su influencia, breve y fulminante, también puede compararse a un contagio celeste: como si fuese un pueblo de pájaros, muchos poetas se echaron a volar. Audacia funesta: la altura inhospitalaria los 
derribó casi inmediatamente" (100-101). El creacionismo de Huidobro lo admira y lo decepciona casi a un mismo tiempo: es una brillante idea que no resiste un examen riguroso: "Su mente era fértil y precisa; además, tuvo buena puntería y disparaba sin cesar ocurrencias y paradojas. Muchas daban en el blanco y otras, después de un brillo momentáneo, se disipaban en humo". Ilustró sus reparos al creacionismo, inventor de realidades ajenas a la realidad, con una rápida reflexión acerca del título de uno de los primeros libros de Huidobro, escrito en francés: Horizon carré. "Un horizonte cuadrado, decía Huidobro, 'es un hecho nuevo, inventado, creado por mí. Antes no existía.' Pero no decía — ¿se daba cuenta? - que se trataba de un hecho imaginario: en la realidad no hay ni puede haber horizontes cuadrados. Incluso puede agregarse que no los hay, tampoco, en el reino de la imaginación: un horizonte cuadrado, más que una realidad imaginaria, es una realidad meramente verbal. No la podemos ver con los ojos, ni pensarla con la mente; en cambio, podemos decirla. La estética creacionista no fue tanto un error como una deducción precipitada de algunas de las ideas del cubismo" ("Decir sin decir: Vicente Huidobro", 1993c: 177-178). He aquí otra virtud del Paz ensayista: la claridad de la expresión y la elegancia de la prosa, siempre ajenas a las jergas teóricas en boga. Pese a sus reticencias ponderadas ante el creacionismo, Octavio Paz dedicó páginas y una memorable conferencia dictada en El Colegio Nacional al análisis del extenso poema Altazor. Sus conclusiones van a contracorriente de la tradicional interpretación del poema, sobre todo en lo que se refiere a su final: "El largo discurso de Altazor se resuelve en una serie de bloques silábicos a un tiempo cristalinos e impenetrables. La crítica ha visto en esta insignificación una prueba del fracaso de Altazor y de la insignificancia final del poema. Creo lo contrario: el fracaso de Altazor — si puede hablarse de fracaso- es otro: no es poético sino espiritual. Y no es un fracaso insignificante sino prometeico: hablamos porque no somos dioses. $Y$ cuando queremos hablar como dioses, perdemos el habla" (181-182). Luego argumenta Paz: "Los dioses, según nos lo cuentan las cosmogonías, hablan estrellas, ríos, montes, caballos, insectos, dragones. Para ellos hablar es crear. Los dioses, al hablar, producen; los hombres, al hablar, relacionan" (182). En esto consiste el verdadero límite al pequeño Dios que aspiró a ser Huidobro y también la razón de la humildad que pedía el mexicano para todas las empresas de los hombres. 
Octavio Paz asegura que Vicente Huidobro y el pintor Roberto Matta constituyen dos excepciones en las relaciones entre Francia y América Latina, porque ambos influyeron en la cultura francesa. Con comprensible modestia, no se incluyó a sí mismo en el señalamiento, pero la recepción de su obra en Francia lo haría encabezar la excepcional trinidad. Roberto Matta participó, desde la plástica, en la aventura del surrealismo y, a la par de Octavio Paz y Gonzalo Rojas desde la poesía, encontró una vía de salida al movimiento estancado durante la Segunda Guerra Mundial. Paz la describe así: "En la pintura surrealista se opera una metamorfosis radical, preparada por Duchamp y realizada por Matta: fusión del erotismo, el humor y la nueva física. Matta introduce una visión no-figurativa: sus cuadros no son transcripciones de realidades vistas o soñadas sino recreaciones de estados anímicos y espirituales. Lo no visto se hace visible o, más exactamente, encarna. Fue un atrevido viraje que hizo cambiar de rumbo a la pintura surrealista y que abrió pistas desconocidas a los jóvenes artistas de los Estados Unidos" ("Rodolfo Matta: vestíbulo", 2001: 188-189). Virajes similares efectuaron Octavio Paz y Gonzalo Rojas para seguir siendo fieles a los principios del surrealismo al tiempo que se alejaban del movimiento con el objeto de encontrar su propia voz poética. En la explosión interior que preside los cuadros de Matta, se cumplen las "nupcias de la pasión y la cosmogonía, de la física moderna y el erotismo [...] Para Matta la revolución y el amor, los cataclismos sociales y las explosiones de la galaxia, son parte de la misma realidad y, en un sentido profundo, riman" (188). Aquí, de paso, quiero dar fe de la generosidad de Matta en los meses finales de Octavio Paz. Luego del incendio que destruyó parte de su biblioteca y de su departamento del Paseo de la Reforma, Octavio Paz encontró refugio en la Casa de Alvarado en el histórico Coyoacán. Apenas se enteró de la siniestra noticia, Matta envió dos de sus espléndidos cuadros para alegrar los ojos de su amigo, ya muy aquejado por el cáncer. Quizá fuera un pago a destiempo por el espléndido poema que Paz le había dedicado bajo el título de: "La casa de la mirada". Es, ciertamente, una genuina prueba de amistad. Matta pintaba para que la libertad no se convirtiera en estatua. "Gran decir", aseguraba Paz. "Por desgracia, como otros artistas de nuestro tiempo - y no de los menores: de Picasso a Pound, a Neruda y Éluard— a veces se ha confundido a las estatuas en el poder con los revolucionarios vivos en la cárcel o el destierro, a los tiranos con los libertadores. No digo esto como queja o 
reproche: tenía que decir mi desacuerdo" (190). Paz, aquí, se refiere a la colaboración de Matta con el régimen castrista. Cuba fue un punto de desacuerdo con el pintor y un punto de coincidencia con el narrador Jorge Edwards, quien fue "persona non grata" en la isla y, por la misma razón, grato colaborador del archipiélago de la revista Vuelta.

El golpe de Estado del 11 de septiembre de 1973 sorprendió a Octavio Paz en Cambridge, Massachusetts, y su reacción no se hizo esperar. El 28 de septiembre, es decir, a unos escasos días de la muerte de $\mathrm{Pa}$ blo Neruda, escribió un texto titulado: "Los centuriones de Santiago". No ponía freno a su indignación: "Espectáculo grotesco y feroz: en la cumbre del monumento un tribunal de pigmeos uniformados y condecorados gesticula, delibera, legisla, excomulga y fusila a los incrédulos. Mientras Nixon se lava las manos sucias de Watergate en el lavamanos ensangrentado que le tiende Kissinger, mientras Bréznev inaugura nuevos hospitales psiquiátricos para disidentes incurables, mientras Chu En-lai agasaja a Pompidou en Pekín y alerta a los europeos occidentales sobre 'el peligro ruso' - los generalitos latinoamericanos hacen otra de las suyas" ("Los centuriones de Santiago", 1996: 432). Pero, inmediatamente, puntualiza que "la indignación puede ser una moral pero es una moral a corto plazo" e invita a hacer un examen de conciencia para sacar las lecciones pertinentes de "la gran tragedia" y de "la gran derrota". Una vez más, pide que uno se acerque a la realidad con humildad y se reconozcan los errores que condujeron al fracaso de la Unidad Popular encabezada por Salvador Allende. Además de las conspiraciones del dinero y de las potencias extranjeras, Octavio Paz subraya que

la izquierda también está en lucha con ella misma. No sólo está dividida en muchas tendencias sino que, más grave y decisivamente, está desgarrada entre la relativa debilidad de sus fuerzas y el carácter geométrico y absoluto de sus programas. Su predicamento es el de aquel que pretende perforar rocas con alfileres. En Europa occidental contrasta la fuerza de los movimientos de izquierda franceses e italianos con la prudente modestia de sus programas; en América Latina sucede exactamente lo contrario (453).

Denuncia la ideología o, mejor dicho, la ideologización de los sueńos de cambio social como la peor intoxicación del siglo y pide mesura: 
Necesitamos elaborar programas que correspondan a nuestra historia y a nuestro presente. A la luz de la terrible experiencia del siglo xx, esos programas tendrán que ser democráticos - aunque no tienen por qué ser copias de las democracias burguesas occidentales. También deberán contener los gérmenes de un futuro socialismo y, ante todo, deberán proponer modelos de desarrollo económico y de organización social que sean menos inhumanos e injustos que los de los regímenes capitalistas y los del 'socialismo burocrático'. No se trata de fundar paraísos sino de dar respuestas reales a la realidad de nuestros problemas (456).

La lección que saca de la experiencia chilena resume bastante fielmente sus posiciones generales sobre el cambio más deseable para América Latina y, hasta diría, para el mundo entero. La izquierda mexicana y, de paso, la izquierda latinoamericana asilada en su país natal, solía editar con mala fe sus críticas a los regímenes que dividían el mundo en dos bloques: si bien no masticaba sus críticas a las izquierdas de toda latitud, tampoco regateaba sus críticas al sistema capitalista.

Gonzalo Rojas ocupa un lugar singular en la relación de Octavio Paz con Chile. Nunca el mexicano le dedicó un ensayo, aunque siempre lo menciona, junto con Nicanor Parra, entre los poetas que conforman su propia generación, es decir, que inauguraron la poesía moderna de Hispanoamérica a partir de 1945 (Por cierto, ignoro la razón del malentendido que distanció a Nicanor Parra de Octavio Paz y que llevó al primero a confesar su arrepentimiento a la revista Rocinante de octubre de 1998, luego de la muerte del mexicano: "Pérdida irreparable para las letras del siglo xx / La peor noticia que puede recibir un lector exigente desde la muerte de Rubén Darío. / Con un punto a favor de Octavio / Que se mantuvo lúcido hasta el fin / No se dejó tragar por el poder / Hubo un malentendido entre nosotros / Pero la culpa la tuve yo / Que la verdad no quede sin ser dicha”).

La amistad entre Paz y Rojas duró más de medio siglo y el encantamiento mutuo resistió, extrañamente, las disensiones políticas, el silencio intermitente entre los encuentros que tuvieron, y la distancia geográfica. El lazo se anudó en 1957 cuando el "adelantado" Gonzalo Rojas publicó en el periódico penquista El Sur una extensa y entusiasta recensión de El arco y la lira y de Libertad bajo palabra: "Desde la lectura del científico estudio del otro mexicano, el universal Alfonso Reyes, intitulado El Deslinde, no leíamos nada tan completo sobre la proble- 
mática de la poesía en español" (“Octavio paz y la poesía"), comentaba Gonzalo Rojas a propósito de El arco y la lira. Hasta podría remontarse más atrás todavía, cuando en 1943 Gonzalo Rojas incluyó en una antología de poesía, publicada en la confidencial revista Antártica, el nombre de Octavio Paz junto a Aimé Césaire y Lautréamont. Huelga recalcar que Gonzalo Rojas fue un lector de primera hora de Octavio Paz en América Latina, uno de los primeros que hizo pública su admiración por el investigador del fenómeno poético que a él lo desvelaba con semejante intensidad. También me consta que siguió siendo un lector de Paz hasta la última hora e incluso, quizá, hasta después del después.

Si en dos ocasiones Octavio Paz estuvo a punto de pisar tierra chilena fue por iniciativa e invitación de Gonzalo Rojas: la primera al Encuentro de Escritores de Concepción en 1962 y la otra, en octubre de 1997, para un recital poético en la Universidad Andrés Bello, a unos meses del fatal incendio en la casa de Paz, que asimismo marcó el inicio de su declive físico y anímico. En la primera ocasión, le escribe a Gonzalo Rojas, en una carta fechada en París el 4 de diciembre de 1961: "Corto y todo, el viaje me emociona. Será una primera visita a Sudamérica - digo primera porque tengo la seguridad de que habrá otras. Una nueva época se inicia para los latinoamericanos; después de años de aislamientos empezamos a hablar entre nosotros, sin necesidad de pasar por Europa". ${ }^{1}$ Pero una exposición de Arte Mexicano en el Grand Palais de París ancló al diplomático mexicano en Francia y le impidió emprender el vuelo a Chile. "Querido Gonzalo - le escribe Paz en una larga carta de explicaciones y disculpas-: en verdad me siento avergonzado. Me dolería que pensases que desdeño tu invitación. Me dolería aún más que tu amistad se enfriase. Comprendo que respondo con un gesto en apariencia esquivo a tu actitud abierta y generosa. No lo creas. Por segunda vez, las circunstancias aplazan mi viaje a Chile. Pero lo haré, sin invitación - y aunque sólo sea para ir a saludarte, abrazarte y pedirte de viva voz, perdón y amistad". Los intercambios epistolares jalonearon los años y los acontecimientos de cada quien. Cuando el exilio de Gonzalo Rojas se volvió excesivamente áspero en Alemania Oriental, Octavio Paz se movilizó para conseguirle un puesto de profesor

${ }^{1}$ Octavio Paz, carta inédita a Gonzalo Rojas. Archivo de Gonzalo Rojas. Todas las citas a continuación provienen de cartas inéditas. 
en la recién creada Universidad Autónoma Metropolitana de la ciudad de México, pero una oferta semejante de Venezuela llegó primero a Rostock. Un año después, en 1976, Paz reitera la invitación al tiempo que su admiración: "Sí, recibí tus poemas. Me gustaron muchísimo. Pero gustar es inexacto: me conmovieron. Tú eres, siempre lo has sido, un poeta verdadero. Si tú me autorizas, podría publicarlos en la revista Plural.// Hablé mucho de ti, de tu poesía y tu situación, con Guillermo Sucre, que te quiere y admira. ¿Te interesaría algo en México? El país es hermoso y, si es cierto que la vida literaria es mezquina, tú como extranjero vivirías al margen de las bajezas y rencillas". Y si bien Paz nunca le dedicó un ensayo, en cambio, en una carta de abril de 1976, se explaya sobre su lectura de los poemas del chileno:

He leído y releído tus poemas. Me han impresionado y conmovido. Reconocí en ellos tus antiguos dones: el arrebato suntuoso, la materia verbal rica y densa. Pero ahora todo se ha purificado y, sin perder cuerpo, se ha vuelto esencial y — ¿por qué no emplear esa palabra? - espiritual. Tu espíritu se ha bañado en el agua del tiempo. Se adivina que has pasado - aunque tú nunca las mencionas expresamente- por experiencias hondas, de esas que nos aniquilan o nos resucitan, nos vuelven tontos o nos hacen sabios: el destierro, la edad, el amor, las muertes. En tus poemas hay un rey ciego y vidente, el ritmo, ese ritmo que es el corazón que arde, fulgura y parpadea (como un ojo y como un astro) en muchas de tus páginas. (No hago sino citarte). Hacía mucho que yo no leía poemas tan intensos, palabras cargadas de la verdad de este mundo y quemadas por el roce del otro. Poesía en los límites y de los límites...

Y como Gonzalo Rojas decidió proseguir su exilio en Venezuela, entonces Octavio Paz le ofreció una casa en las revistas Plural y Vuelta que fundó en México: "No olvides enviar más cosas para Vuelta. Es tu revis$t a$, tu casa”, le reitera Paz en cada carta. Una pequeńa estadística bastaría para corroborar la presencia de Gonzalo Rojas en su "casa" mexicana llamada Vuelta: en ella publicó 32 poemas, casi un libro entero, y es así el poeta más publicado en la vida entera de la revista, por encima de Octavio Paz que solo se "auto publicó" 20 poemas. Así se explica también por qué Gonzalo Rojas es un poeta tal vez más leído en México que en Chile, un poeta que los mexicanos adoptaron e hicieron suyo cuando sus compatriotas pretendieron echarlo del aire. 
Como si hiciera falta aportar más pruebas de esta amistad excepcional, quisiera terminar revelando un hecho hasta ahora desconocido. Cuando se instituyó el Premio de Poesía y Ensayo Octavio Paz en 1998, junto con la Fundación que llevaba su nombre, el jurado se reunió en la Casa de Alvarado para deliberar y escoger al galardonado de la primera edición. Octavio Paz, ya muy aquejado por el cáncer, no formaba parte del jurado. Sin embargo, apareció inesperadamente en la sala donde sesionaba el jurado. Se disculpó por la irrupción y pidió que, por favor, tomaran en cuenta la sugerencia que llevaba escrita en un papelito que depositó sobre la mesa. Solo había escrito dos palabras: "Gonzalo Rojas". Huelga precisar que el chileno también era el gallo de los integrantes del jurado. Como se sabe, Gonzalo Rojas llegó a México a recoger el Premio la tarde en que murió Octavio Paz y le tocó encarnar la voz de la poesía frente al féretro del mexicano en el vestíbulo del Palacio de Bellas Artes. En la imaginación de muchos mexicanos, ese día la voz de Gonzalo Rojas habló por la voz que ya no podía oírse, como si la poesía fuera un río ininterrumpido que fluyera de un individuo a otro, de una voz a otra, cuando estas expresan el mismo lenguaje de la poesía verdadera.

A fines de marzo de 2014, en la ciudad de México, se festejó el primer centenario de Octavio Paz. Es una centuria que coincide con la Historia de un continente, con el pasado de la poesía moderna de Hispanoamérica, sin duda, su mejor siglo. Pero ahora comienza la segunda centuria de existencia del poeta mexicano: aquella que inicia con la lectura que cada nueva generación, con su hambre nueva y distinta como decía Baudelaire, hará de su obra. Porque una obra poética de la magnitud de la de Octavio Paz no es una tumba, sino una casa de cristal, donde él vive y vivirá por mucho tiempo más, hasta que desaparezca el último lector.

Quisiera concluir reproduciendo a continuación el poema de Gonzalo Rojas: "Urgente a Octavio Paz":

Urgente a Octavio Paz

77 es el número de la germinación de la otra

Palabra, en lo efímero

de la vuelta

mortal

con tanto Octavio todavía 
por aprender del aire, con tanta ceiba

libre que uno pudiera ser, si uno pudiera

ser ceiba en la tormenta con exilio

y todo en la germinación del número

de esta América de sangre con ventisquero

y trópico y grandes ríos

de diamante, sin más tinta

que esta respiración para escribir tu nombre más allá de las nubes

de México ciego hasta cómo decirlo

al otro México que somos todos cuando la aorta

del amanecer abre ritual el ritmo de las violetas

carnales de la Poesía, las muchachas de bronce que marchaban

airosas al sacrificio

desnudas al matadero por nosotros antes de parirnos

altas en su doncellez hacia lo alto de los cóndores

desde donde jugamos mientras caemos páginas

tras página en este juego de adivinos

del siempre y el nunca de las estrellas y tú te llamas por ejemplo

77 ángeles como Blake y yo mismo me llamo

77 especies de leopardos voladores porque es justo que el aire

vuelva al aire del pensamiento y no muramos

de muerte y esto sea el principio Octavio

de otro principio y otro, y además no vinimos

aquí a esto.

\section{BiBLIOGRAFÍA}

Paz, Octavio. Obras Completas, tomo 1, La casa de la presencia, poesía e historia. México: Fondo de Cultura Económica, 1993 a.

Paz, Octavio. Obras Completas, tomo 2, Excursiones/Incursiones, Dominio extranjero. México: Fondo de Cultura Económica, 1993b.

Paz, Octavio. Obras Completas, tomo 3, Fundación y disidencia: dominio hispánico. México: Fondo de Cultura Económica, 1993c.

Paz, Octavio. Obras Completas, tomo 9, Ideas y costumbres I. La letra y el cetro. México: Fondo de Cultura Económica, 1996. 
Paz, Octavio. Obras completas, tomo 14, Miscelánea II. México: Fondo de Cultura Económica, 2001.

Rojas, Gonzalo. "Octavio Paz y la poesía”, El Sur, Concepción, Chile (26 de mayo de 1956).

Sheridan, Guillermo. Poeta con paisaje: ensayos sobre la vida de Octavio Paz. México: Era, 2004.

FECHA DE RECEPCIÓN: 24 de abril de 2014.

Fecha de aCeptación: 16 de junio 2014. 